\title{
Leaf photosynthesis, fluorescence response to salinity and the relevance to chloroplast salt compartmentation and anti-oxidative stress in two poplars
}

\author{
Ruigang Wang · Shaoliang Chen · Lin Deng · \\ Eberhard Fritz · Aloys Hüttermann · Andrea Polle
}

Received: 26 June 2006/ Revised: 28 September 2006/ Accepted: 27 June 2007 / Published online: 25 July 2007

(C) Springer-Verlag 2007

\begin{abstract}
In a 16-day study, the effect of increasing soil $\mathrm{NaCl}$ on leaf photosynthesis, chlorophyll $a$ fluorescence, chloroplast ion compartmentation, variations of SOD (superoxide dismutase) and POD (peroxidase) isoenzymes and the relevance to salt resistance were investigated in seedlings of Populus euphratica Oliv. (P. euphratica) (saltresistant) and rooted cuttings of $P$. "popularis 35-44" ( $P$. popularis) (salt-sensitive). Initial salinity caused a rapid decline of net photosynthetic rate $(\mathrm{Pn})$ and unit transpiration rate (TRN) in P. euphratica, resulting from the $\mathrm{NaCl}-$ induced stomatal closure. In a longer-term of salinity, $\mathrm{CO}_{2}$ assimilation in $P$. popularis was severely reduced whereas stressed $P$. euphratica maintained a relatively higher and constant level of Pn. Pn-Ci curves showed that salt stress (12 days) reduced $\mathrm{CO}_{2}$ saturation point (CSP), $\mathrm{CO}_{2}$ saturated $\mathrm{Pn}\left(\mathrm{CSP}_{n}\right)$, and carboxylation efficiency $(\mathrm{CE})$, but increased $\mathrm{CO}_{2}$ compensation point (CCP) in the two genotypes. Similarly, salinity lowered light saturation point (LSP), light saturated $\mathrm{Pn}\left(\mathrm{LSP}_{n}\right)$, and apparent quantum yield (AQY) in both genotypes but the inhibitory effect of $\mathrm{NaCl}$ on light reaction was more pronounced in $P$. popu-
\end{abstract}

Communicated by H. Rennenberg.

R. Wang $\cdot$ S. Chen $(\bowtie) \cdot$ L. Deng

College of Biological Sciences and Technology,

Beijing Forestry University, Box 162,

Beijing 100083, People's Republic of China

e-mail: Lschen@bjfu.edu.cn

E. Fritz · A. Hüttermann · A. Polle

Institut für Forstbotanik,

Georg-August-Universität Göttingen,

Büsgenweg 2, 37077 Göttingen, Germany laris, as compared to P. euphratica. Chlorophyll a fluorescence data indicated that a longer-term of salt stress (12 days) exhibited a marked influence on fluorescence parameters of $P$. popularis in both dark- and light-adapted states: (a) $\mathrm{NaCl}$ inhibited the maximal efficiency of PSII photochemistry $(\mathrm{Fv} / \mathrm{Fm})$ due to the salt-induced increase of Fo (the minimal fluorescence) and the marked decline of Fm (the maximal fluorescence); (b) salinity decreased coefficient of photochemical quenching (qP) but markedly elevated coefficient of nonphotochemical quenching (qN) in the light-adapted state. In contrast, there were no corresponding changes of chlorophyll $a$ fluorescence in salinised P. euphratica. X-ray microanalysis results showed that salinity caused salt accumulation in the chloroplasts of $P$. popularis in which $\mathrm{Na}^{+}$and $\mathrm{Cl}^{-}$increased up to 42 and $221 \mathrm{mmol} \mathrm{dm}^{-3}$, respectively. Great buildup of $\mathrm{Na}^{+}$ and $\mathrm{Cl}^{-}$in chloroplasts of $P$. popularis may exhibit direct and indirect restrictions on dark and light reactions. The activity of SOD isoenzymes (CuZn-SOD I and CuZn-SOD II) and POD isoenzymes in $P$. popularis decreased with increasing exposure period, and leaf malondialdehyde (MDA) content and membrane permeability (MP) increased correspondingly. In contrast to $P$. popularis, stressed $P$. euphratica maintained activity of SOD and POD isoenzymes and there was no significant increase of MDA and MP during the period of salt stress. In conclusion, $P$. euphratica plants exhibited a higher capacity to maintain the activity of anti-oxidant enzymes and restrict salt accumulation in the chloroplasts, the photosynthesis processes were less restricted consequently.

Keywords $\mathrm{NaCl} \cdot P$. euphratica $\cdot P$. popularis . Photosynthesis · Chlorophyll $a$ fluorescence · SOD isoenzymes · POD isoenzymes · Chloroplast ion compartmentation $\cdot \mathrm{X}$-ray microanalysis 


\section{Introduction}

Populus spp. are one of the most important tree species for afforestation in north China, but the productivity of fastgrowing poplars is usually restricted by soil salinity. Comparative studies have been carried out to determine the salt tolerance of several poplar genotypes (Ma et al. 1997; Fung et al. 1998). Results showed that salt stress reduced photosynthesis of poplar leaves, but there was much variation in salt tolerance among genotypes of Populus. Net photosynthetic rate $(\mathrm{Pn})$ of highly salinised $P$. euphratica Oliv. $(P$. euphratica) was less inhibited as compared to the hybrid, $P$. talassica Kom $\times(P$. euphratica + Salix alba L.) (Ma et al. 1997). In general, the Pn reduction in response to an initial osmotic shock caused by $\mathrm{NaCl}$ was mainly the result of decreased stomatal conductance (Chen et al. 2002a), while in a longer-term of severe salt stress, the declined Pn was largely due to non-stomatal limitations (Ma et al. 1997).

Salinised poplar trees transport $\mathrm{Na}^{+}$and $\mathrm{Cl}^{-}$from roots to the shoots under $\mathrm{NaCl}$ stress, causing a great buildup of salt in leaves (Chen et al. 2001, 2002b, 2003). A recent study revealed that $\mathrm{Na}^{+}$preferential accumulated in the apoplast relative to vacuole in succulent $P$. euphratica leaf cells (Ottow et al. 2005a). Salt accumulation in leaves may cause physiological disturbances if mesophyll cells could not restrict their entry into the cytoplasm (Greenway and Munns 1980). Ma et al. (1997) found that the reduction of photosynthesis under high salt treatment was not due to damage of the photosynthetic apparatus, but more likely due to the inhibition of dark reaction since chlorophyll $a$ fluorescence was not reduced by salinity. However, the ion compartmentation in chloroplasts and the effects of salts on light and dark reaction needs to be investigated.

Apart from salt-induced osmotic stress and ion toxicity, an increasing body of evidence suggests that high salinity also induces oxidative stress (Hernández et al. 1993, 1995, 1999, 2000; Gosset et al. 1996; Gómez et al. 1999; Savouré et al. 1999). It is suggested that plant salt resistance may partly depend on anti-oxidant capacities under saline conditions. Anti-oxidant enzymes, e.g. superoxide dismutase (SOD) and peroxidase (POD) play a key role in plant antioxidative stress (Takahashi and Asada 1983; Fridovich 1986; Asada and Takahashi 1987; Elstner 1987; Hassan and Scandalios 1990; Bowler et al. 1992; Asada 1994; Hernández et al. 1995; Alscher et al. 2002; Shigeoka et al. 2002). Tsugane et al. (1999) suggested that salt-induced activities of anti-oxidant enzymes increased plant salinity resistance. In accordance, increasing expression of SOD in Arabidopsis and tobacco enhanced salt tolerance of transgenic plants (Badawi et al. 2004; Wang et al. 2004).

There are drastic differences of salt tolerance in $P$. $e u$ phratica, $P . \times$ euramericana $\mathrm{cv} . \mathrm{I}-214(P . \mathrm{cv}$. Italica) and $P$. "popularis 35-44" ( $P$. popularis) in terms of timing that leaf damage occurred (Chen et al. 2002b). Under the same saline conditions, $P$. popularis and $P$. cv. I-214 exhibited a clear symptom of leaf injury whereas there was no leaf necrosis in $P$. euphratica (Chen et al. 2002b; Wang et al. 2006). We found that the increased membrane permeability in salt-sensitive $P$. popularis leaves was associated with salt-induced lipid peroxidation, which was likely due to the drastic decline of SOD and POD activity (Wang et al. 2006). It seemed that stressed $P$. popularis was unable to scavenge stress-induced reactive oxygen species (ROS), thus leading to an uncontrolled oxidation in a longer-term of salt stress. In comparison, salt-tolerant $P$. euphratica maintained activity of SOD and POD during the period of salt stress and limited lipid peroxidation, which contributing to membrane integrity maintenance (Wang et al. 2006). However, how $P$. euphratica retained the activity of antioxidant enzymes during the period of salt stress has not been investigated. Salt-induced changes in isoenzymes of SOD and POD are helpful to elucidate the anti-oxidant capacity in $P$. euphratica.

Collectively, the objective of this study was to evaluate leaf photosynthesis response to salinity and the relevance to $\mathrm{NaCl}$-induced anti-oxidative stress in two poplar genotypes, salt-tolerant $P$. euphratica and salt-sensitive $P$. popularis. We attempted to investigate: (a) salt compartmentation in chloroplasts and the inhibitory effects of salt ions on light and dark reaction in $\mathrm{CO}_{2}$ assimilation; (b) genotypic differences in salt-induced changes in isoenzymes of SOD and POD and the relevance to anti-oxidative stress.

\section{Materials and methods}

\section{Plant materials}

One-year-old seedlings of Populus euphratica Oliv. (P. euphratica) and 1-year-old rooted cuttings of $P$. "popularis 35-44" ( $P$. popularis) were used in this experiment. Hardwood cuttings of $P$. popularis were obtained from nursery of Beijing Forestry University (China) and seedlings of $P$. euphratica were from Xinjiang Uygur Autonomous Region of China. On 6th April 2004, plants were planted in $10 \mathrm{~L}$ individual pots containing nursery soil and sand (soil:sand $=2: 1$ ). Potted plants were kept well watered and received $1 \mathrm{~L}$ of full strength Hoagland's nutrient solution every 2 weeks. Potted plants were placed in a greenhouse at nursery of Beijing Forestry University prior to the initiation of salt treatment (July).

Salt treatment and soil analysis

Plants were subjected to 16 days of increasing $\mathrm{NaCl}$ stress. Saline treatment was imposed by top watering of $1 \mathrm{~L}$ of 50 , 
100,150 , and $200 \mathrm{mM} \mathrm{NaCl}$ (in full strength Hoagland's nutrient solution) on day 1 , day 4 , day 8 and day 12 , respectively. Control plants were kept well watered and weekly fertilized by watering $1 \mathrm{~L}$ of full strength Hoagland's nutrient solution with no addition of $\mathrm{NaCl}$. Visible symptoms of salt damage were observed in aged leaves of $P$. popularis after 12 days of exposure to salinity. Leaves exhibited chlorosis or necrosis at the edge of leaves, then leaves developed necrosis areas prior to abscission. In contrast, no visible damage and leaf abscission were seen in $P$. euphratica plants during the period of salt treatment.

Soil $\mathrm{NaCl}$ increment was examined during the period of increasing salt stress. Soil sample were taken at $20-30 \mathrm{~cm}$ depth in pots and soil water content was determined. Extracts of soil samples (dried soil:deionised water $=1: 5$, weight/volume) were used for cations and $\mathrm{Cl}^{-}$analysis. $\mathrm{Na}^{+}$, $\mathrm{K}^{+}, \mathrm{Ca}^{2+}$ and $\mathrm{Mg}^{2+}$ were measured by an atomic absorption spectrophotomer (Perkin-Elmer 2280) and $\mathrm{Cl}^{-}$by silver titration (Chen et al. 2001). Ion concentrations (mmol/L) were calculated as: ion content (ion $\mathrm{mmol} / \mathrm{dried}$ soil weight $\mathrm{kg}$ )/soil water content (water $\mathrm{kg} /$ dried soil weight $\mathrm{kg}$ ) (Chen et al. 2001). Soil analysis showed that $\mathrm{NaCl}$ concentration in the soil reached $326 \mathrm{mM}$ after 16 days of salt treatment, whereas soil $\mathrm{NaCl}$ level in the control treatment was maintained at approximately $20 \mathrm{mM}$ throughout the experiment. $\mathrm{K}^{+}, \mathrm{Ca}^{2+}$ and $\mathrm{Mg}^{2+}$ concentrations in the soil were not significantly changed by $\mathrm{NaCl}$ treatment.

\section{Gas exchange}

Gas exchange of upper mature leaves (leaf index number 6-8 from shoot tip, in general these leaves have higher gas exchange values) was measured on day 1 (1, 4, 8 and $24 \mathrm{~h}$ after initiation of salt stress), day 8, day 12 and day 16 , respectively. Net photosynthetic rate $(\mathrm{Pn})$, stomatal conductance (Gs) and transpiration rate (TRN) were measured at 8:30-10:00 a.m. using a Ciras-2 portable photosynthesis system (PP-systems, UK) under natural conditions where the air temperature $\left(T_{\text {air }}\right)$ was $31.3-36.2^{\circ} \mathrm{C}$ and photosynthetically active radiation (PAR) was 974-1,004 $\mu \mathrm{mol}$ $\mathrm{m}^{-2} \mathrm{~s}^{-1}$, supplied by cool white fluorescent lamps supplemented with dysprosium lamps. Leaf temperature $\left(T_{\text {leaf }}\right)$ ranged from 31.1 to $36.3^{\circ} \mathrm{C}$ during the period of gas exchange measurement. After day 12, green parts of $P$. popularis leaves were used for gas exchange measurements since salt-stressed plants exhibited chlorosis or necrosis at the edge of leaves. Three individual plants per treatment were examined at each sampling time.

Pn versus Ci relationships

On day $12, \mathrm{Pn}-\mathrm{Ci}$ curves of upper mature leaves (leaf index number 6-8 from shoot apex) were measured over a range of intercellular $\mathrm{CO}_{2}$ concentrations $(\mathrm{Ci})(0,30,60$, 100, 200, 300, 400, 500, 600, 800, 1,000 $\mathrm{mol} \mathrm{mol}^{-1}$ ) controlled by a mini $\mathrm{CO}_{2}$ cartridge. PAR was 1,081$1,238 \mu \mathrm{mol} \mathrm{m} \mathrm{m}^{-2} \mathrm{~s}^{-1}$ supplied by cool white fluorescent lamps supplemented with dysprosium lamps. $T_{\text {air }}$ and $T_{\text {leaf }}$ was $33.5-36.7$ and $33.0-37.1^{\circ} \mathrm{C}$, respectively. Leaves were allowed at least 5-6 min to adjust to the stepwise increased $\mathrm{CO}_{2}$ concentration in the cuvette. The averaging time period for gas exchange measurement was ca. $2 \mathrm{~min}$ at each $\mathrm{CO}_{2}$ concentration after the steady-state value of gas exchange was reached. $\mathrm{CO}_{2}$ saturation point and $\mathrm{CO}_{2}$ saturated $\mathrm{Pn}$ were calculated by linear quadratic equation regression from data measured over a range of $\mathrm{Ci}$ $\left(0 \rightarrow 950 \mu \mathrm{mol} \mathrm{mol}^{-1}\right)$. The initial slope of the linear portion of the $\mathrm{Pn}-\mathrm{Ci}$ curve represents the carboxylation efficiency (CE) and the intercept of the $\mathrm{Ci}$ axis represents the $\mathrm{CO}_{2}$ compensation point. Three individual plants per treatment were examined in both genotypes.

\section{Pn versus PAR relationships}

On day 13, Pn-PAR curves of upper mature leaves (leaf index number 6-8 from the shoot tip) were measured over a range of PAR $(1,800,1,600,1,400,1,200,1,000,800$, $600,500,400,300,200,100,80,60,40,20 \mu \mathrm{mol} \mathrm{m}{ }^{-2} \mathrm{~s}^{-1}$ ) that controlled by a fan-cooled white Halogen light source. $T_{\text {air }}$ and $T_{\text {leaf }}$ was $29.6-41.3$ and $28.7-39.5^{\circ} \mathrm{C}$ during the observation period (supplemented irradiance, $>1,000$ $\mu \mathrm{mol} \mathrm{m} \mathrm{m}^{-2} \mathrm{~s}^{-1}$ caused transitory higher temperature in leaf cuvette although a fan-cooled light source was used). Light saturation point and light saturated Pn were calculated by natural logarithm regression from data measured over a range of PAR $\left(20-1,800 \mu \mathrm{mol} \mathrm{m} \mathrm{m}^{-2}\right)$. The initial slope of the linear portion of the Pn-PAR curve represents the apparent quantum yield (AQY) and the intercept of the PAR axis represents the light compensation point. Three individual plants per treatment were examined in both genotypes.

\section{Chlorophyll $a$ fluorescence}

On day 2 and day 12, chlorophyll $a$ fluorescence of 0.5 -h dark-adapted leaves was measured using the same leaf for gas exchange measurement (leaf index number 6-8 from shoot apex, green parts were used for fluorescence measurement in salt-injured $P$. popularis leaves on day 12). Chlorophyll $a$ fluorescence was measured using a PAM-2100 Fluorometer (Heinz Walz GmbH, Germany) at 8:30-10:00 a.m. and air temperature was $32.2-36.2^{\circ} \mathrm{C}$. The minimal fluorescence level (Fo) was determined by a modulated light, which was lower enough $\left(<0.1 \mu \mathrm{mol} \mathrm{m} \mathrm{m}^{-2} \mathrm{~s}^{-1}\right)$ not to induce any significant variable fluorescence and the maximal fluorescence level (Fm) was determined by a $0.8 \mathrm{~s}$ 
saturating pulse at $15,000 \mu \mathrm{mol} \mathrm{m} \mathrm{m}^{-2} \mathrm{~s}^{-1}$ on dark-adapted leaves ( $30 \mathrm{~min}$ ). Then the leaf was continuously illuminated with a white actinic light at a light intensity of $600 \mu \mathrm{mol}$ $\mathrm{m}^{-2} \mathrm{~s}^{-1}$, the steady-state value of fluorescence $(\mathrm{Fs})$ was reached within about 5-6 min and thereafter was recorded and a second saturating pulse at $15,000 \mu \mathrm{mol} \mathrm{m}^{-2} \mathrm{~s}^{-1}$ was imposed to determine the maximal fluorescence level in the light-adapted state $\left(\mathrm{Fm}^{\prime}\right)$. The modulation frequency of measuring light source was $20 \mathrm{kHz}$. Following fluorescence parameters were calculated based on the above measurements:

1. Maximal efficiency of PSII photochemistry in the dark-adapted state (Fv/Fm);

2. Photochemical quenching coefficient $\mathrm{qP}=\left(\mathrm{Fm}^{\prime}-\mathrm{Fs}\right) /$ (Fm' - Fo);

3. Nonphotochemical quenching coefficient $\mathrm{qN}=(\mathrm{Fm}-$ $\left.\mathrm{Fm}^{\prime}\right) /(\mathrm{Fm}-\mathrm{Fo})$.

Plant harvests

Destructive harvests were carried out after 2, 8, 12 and 16 days of exposure to the saline treatment and three replicated plants per treatment were harvested at each sampling time. Leaves in upper shoot, leaf index number 4-10 from shoot apex were sampled for biochemical analysis, including soluble protein content, malondialdehyde (MDA) content, membrane permeability and isoforms of SOD and POD. Green parts in salt-injured $P$. popularis leaves were collected for biochemical analysis since visible symptoms of salt damage (leaves exhibited chlorosis or necrosis at the edge of leaves) were observed after 12 days of exposure to salinity.

\section{MDA content}

MDA content was measured according to Heath and Packer (1968). Approximately $0.5 \mathrm{~g}$ (fresh weight) leaf tissue was homogenized in $1.5 \mathrm{~mL}$ of $5 \%$ trichloroacetic acid (TCA) (w/v). The homogenate was centrifuged at $1,500 \mathrm{~g}$ for $10 \mathrm{~min}$, and then the supernatant was diluted to $10 \mathrm{~mL}$. A $2 \mathrm{~mL}$ of the diluted extract was mixed with $2 \mathrm{~mL}$ 0.67\% 2-thiobarbtiuric acid (TBA) (weight/volume). The mixture was incubated in boiled water (95$100^{\circ} \mathrm{C}$ ) for $30 \mathrm{~min}$, then centrifuged at $1,500 \mathrm{~g}$ for $10 \mathrm{~min}$. Absorbencies of the aqueous phase at 450, 532 and $600 \mathrm{~nm}$ were measured, respectively. MDA content in the aqueous phase was calculated based on the following formula:

$\mathrm{C}(\mu \mathrm{mol} / \mathrm{L})=6.45 \times\left(A_{532}-A_{600}\right)-0.56 \times A_{450}$
Membrane permeability

Thirty fresh leaf discs, $0.2 \mathrm{~cm}$ in diameter, were immersed in $10 \mathrm{~mL}$ distilled water and a subsequent $30 \mathrm{~min}$ vacuum was applied. Electrical conductivity $\left(E_{1}\right)$ was then measured with a DDS-307 conductivity meter (Shanghai Precision \& Scientific Instrument) at room temperature. Afterwards, leaf discs were incubated in boiled water (95$100^{\circ} \mathrm{C}$ ) for $30 \mathrm{~min}$ and electrical conductivity $\left(E_{2}\right)$ was measured at room temperature. Leaf membrane permeability was calculated as: $E_{1} / E_{2} \times 100 \%$.

\section{Analysis SOD and POD isoenzymes}

Extracting SOD and POD were followed as per Dhindsa et al. (1981). Approximately $0.5 \mathrm{~g}$ (fresh weight) leaf tissue was homogenized on ice in $2 \mathrm{~mL}$ cold $0.05 \mathrm{M}$ sodium phosphate buffer ( $\mathrm{pH}$ 7.8) containing 1\% PVPP-40. The homogenate was centrifuged at $10,000 \mathrm{~g}$ for $20 \mathrm{~min}$ at $4^{\circ} \mathrm{C}$ and the supernatant was diluted to $5 \mathrm{~mL}$. Then total protein content was determined according to Bradford (1976) using bovine serum albumin as standard. The supernatant was used as crude extracts for determination of SOD and POD isoenzymes. In brief, $30 \mu \mathrm{g}$ of soluble protein were applied to native polyacrylamide gel electrophoresis at $4^{\circ} \mathrm{C}$ using a stacking gel $(4 \% \mathrm{w} / \mathrm{v})$ and a separating gel $(10 \% \mathrm{w} / \mathrm{v})$, respectively (Wang et al. 2004). Thereafter, SOD activity was detected by staining with riboflavin and nitroblue tetrazolium, as described by Beauchamp and Fridovich (1971). POD activity was detected by staining with acetic acid and benzidine, as described by Ros Barceló et al. (1987).

Different types of SOD were identified by adding inhibitors to the staining solution, such as $5 \mathrm{mmol} / \mathrm{L} \mathrm{KCN}$ to inhibit CuZn-SOD activity, and $10 \mathrm{mmol} / \mathrm{L} \mathrm{H}_{2} \mathrm{O}_{2}$ to inhibit CuZn-SOD and Fe-SOD activities (Bridges and Salin 1981; Almansa et al. 1989).

X-ray microanalysis of $\mathrm{Na}^{+}$and $\mathrm{Cl}^{-}$in chloroplast

At the final harvest time (day 16), leaves (leaf index number 6-8 from shoot tip) were sampled from control and salt stressed plants of $P$. euphratica and $P$. popularis, respectively. Green parts were collected in salt-injured $P$. popularis leaves. Standard procedures required for sample preparation were followed as per Fritz (1989). A brief description is given.

\section{Sampling and freeze-drying}

Leaf segments, $2-3 \mathrm{~mm}$ long and $1-2 \mathrm{~mm}$ wide were cut along the branch veins adjacent to the central vein. Then 
samples were immediately placed into aluminium sample holders and rapidly frozen in a 2:1 mixture of propane:isopentane at the temperature of liquid nitrogen. Samples were vacuum freeze-dried at $-60^{\circ} \mathrm{C}$ for $72 \mathrm{~h}$ and then slowly allowed to equilibrate to room temperature (ca $22^{\circ} \mathrm{C}$ ) over a period of $24 \mathrm{~h}$. Then samples were stored over silica gel until infiltration in plastic.

\section{Infiltration and polymerization}

Freeze-dried leaves were transferred into vacuum-pressurechambers, and infiltrated in ether at $27^{\circ} \mathrm{C}$ overnight before infiltrating with plastic. Plastic used was a 1:1 mixture of styrene and butyl methacrylate containing $1 \%$ benzoylperoxide stabilized with $50 \%$ phthalate. Infiltration with plastic was carried out in following steps: 1:1 ether:plastic for $24 \mathrm{~h}, 1: 3$ ether:plastic for $24 \mathrm{~h}$, and finally $100 \%$ plastic for $24 \mathrm{~h}$. Following infiltration, samples were transferred into gelatine capsules and polymerised at $60^{\circ} \mathrm{C}$ for $12 \mathrm{~h}$, then transferred into $30^{\circ} \mathrm{C}$ oven and polymerised for at least 7 days.

\section{Cutting}

After polymerisation, samples were cut into $1 \mu \mathrm{m}$ thick sections using dry glass knife with an ultramicrotome (Ultracut E, Reichert-Jung, Vienna, Austria). The slices were mounted in copper grids (mesh 50), coated with carbon and stored over silica gel until analysis.

\section{$X$-ray microanalysis}

Leaf sections were analysed in a Phillips EM 420 electron microscope equipped with the energy dispersive system EDAX DX-4 (EDAX International, Mahwah, NJ 07430, USA). The operating parameters were as follows: accelerating voltage, $120 \mathrm{kv}$; take-off angle, $25^{\circ}$ and the time for collecting X-rays was 60 live seconds. Probe measurements were made on chloroplasts in spongy and palisade mesophyll cells and the magnification was at $\times 6350$. Ten to twenty measurements were taken from each leaf section. The X-ray spectra were processed with EDAX DX-4 software after manual fitting of the background. Concentrations of the elements at the analysed sites were determined by analytical calibration standard (Fritz and Jentschke 1994).

\section{Data analysis}

All data were subjected to oneway ANOVA and significant differences between means were determined by Duncan's multiple-range test. Unless otherwise stated, differences were considered statistically significant when $P<0.05$.

\section{Results}

Photosynthesis response to salinity

Gas exchange of the two genotypes differed greatly in response to the initial salinity $(50 \mathrm{mM} \mathrm{NaCl})$. Net photosynthetic rate $(\mathrm{Pn})$, stomatal conductance $(\mathrm{Gs})$ and unit transpiration rate (TRN) in $P$. euphratica rapidly declined after 1-4 h of salt stress, then returned to control levels at $24 \mathrm{~h}$, whereas there were no corresponding changes in stressed P. popularis plants (Fig. 1). In a longer-term of increasing salinity, gas exchange of salinised $P$. popularis markedly decreased after 8 days of stress, and continuously dropped to the lowest level on day 16 (Fig. 1). In comparison, NaCl-stressed P. euphratica plants maintained a relatively higher and constant level of Pn, Gs and TRN although salinity significantly lowered the gas exchange (Fig. 1).

Pn versus PAR under salt stress

Compared with control P. popularis plants, control P. euphratica plants had typically lower light compensation point (LCP), light saturation point (LSP), light saturated Pn $\left(\mathrm{LSP}_{n}\right)$, and apparent quantum yield (AQY) (Table 1). Generally, salinity increased LCP but lowered LSP, LSP $_{n}$ and AQY in the two genotypes (Table 1). However, the effects of $\mathrm{NaCl}$ on these parameters were much less pronounced in $P$. euphratica as compared to $P$. popularis (Table 1).

Pn versus Ci under salt stress

Data from Pn-Ci curves showed that salinity reduced $\mathrm{CO}_{2}$ saturation point (CSP), $\mathrm{CO}_{2}$ saturated $\mathrm{Pn}\left(\mathrm{CSP}_{n}\right)$, carboxylation efficiency (CE) but increased $\mathrm{CO}_{2}$ compensation point (CCP) in both genotypes (Table 2). Compared with $P$. euphratica, the salt-induced increase of CCP was more pronounced in $P$. popularis (Table 2).

Chlorophyll $a$ fluorescence response to salt stress

Initial salt stress (day 2) did not influence the minimal fluorescence level (Fo) and the maximal fluorescence level (Fm) in dark-adapted leaves of both genotypes although $P$. euphratica plants had typically lower Fo and Fm (Table 3). In a longer-term of salinity (12 days), visible change of chlorophyll $a$ fluorescence was only observed in P. рориlaris leaves: (a) the maximal efficiency of PSII photochemistry $(\mathrm{Fv} / \mathrm{Fm})$ in the dark-adapted state significantly decreased due to the salt-induced increase of Fo and the marked decline of Fm (Table 3); (b) salt stress significantly decreased coefficient of photochemical quenching $(\mathrm{qP})$ in 
Fig. 1 Effects of $\mathrm{NaCl}$ on leaf net photosynthetic rate $(P n)$, stomatal conductance $(G s)$ and unit transpiration rate $(T R N)$ of $P$. euphratica and $P$. popularis plants. Gas exchange of upper mature leaves (leaf index number 6-8 from the shoot apex) were measured at 8:3010:00 a.m. under natural conditions where the air temperature $\left(T_{\text {air }}\right)$ was $31.3-$ $36.2^{\circ} \mathrm{C}$ and photosynthetically active radiation (PAR) was 974-1,004 $\mu \mathrm{mol} \mathrm{m}{ }^{-2} \mathrm{~s}^{-1}$, which was supplied by cool white fluorescent lamps supplemented with dysprosium lamps. Leaf temperature $\left(T_{\text {leaf }}\right)$ ranged from 31.1 to $36.3^{\circ} \mathrm{C}$ during the period of gas exchange measurement. Each point is the mean of three plants and bars represent the standard error of the mean. Asterisk (*) represents significant difference at $P<0.05$ between control and $\mathrm{NaCl}$ treatment
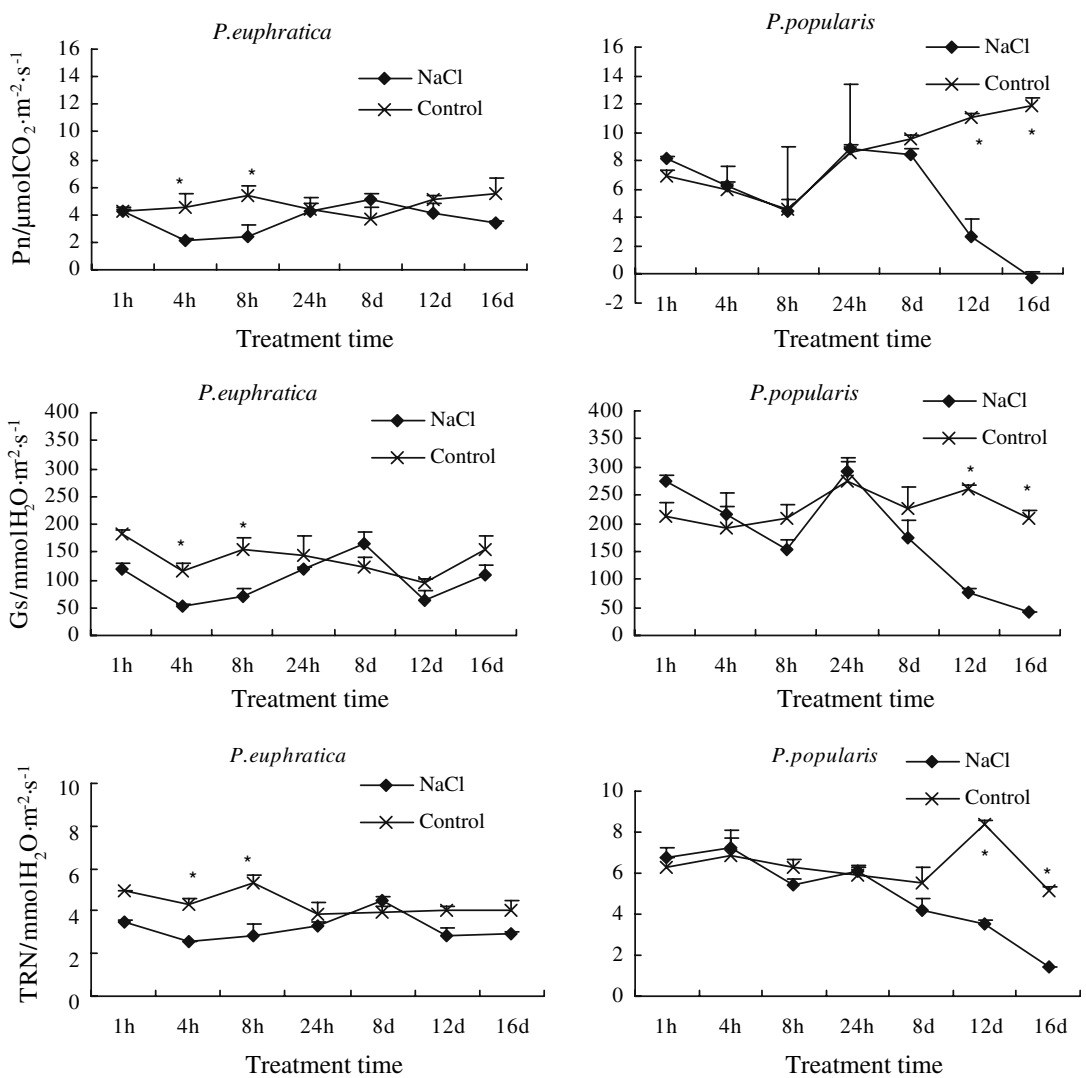

Table 1 Effects of $\mathrm{NaCl}$ on light compensation point (LCP), light saturation point (LSP), light saturated Pn $\left(\mathrm{LSP}_{n}\right)$ and apparent quantum yield (AQY) in leaves of $P$. euphratica and $P$. popularis

\begin{tabular}{llcccc}
\hline Species & Treatments & LCP $\mu \mathrm{mol} \mathrm{m}^{-2} \mathrm{~s}^{-1}$ & LSP $\mu \mathrm{mol} \mathrm{m}^{-2} \mathrm{~s}^{-1}$ & $\mathrm{LSPn} \mu \mathrm{molCO}_{2} \mathrm{~m}^{-2} \mathrm{~s}^{-1}$ & $\mathrm{AQY} \mu \mathrm{mol} \mathrm{CO} 2 / \mu \mathrm{mol} \mathrm{photon}$ \\
\hline P.euphratica & Control & $37 \pm 4.23 \mathrm{~b}$ & $900 \pm 37.2 \mathrm{a}$ & $7.5 \pm 0.40 \mathrm{a}$ & $0.0166 \pm 0.0018 \mathrm{a}$ \\
& $\mathrm{NaCl}$ & $79 \pm 6.16 \mathrm{a}$ & $500 \pm 5.21 \mathrm{~b}$ & $2.5 \pm 0.52 \mathrm{~b}$ & $0.0093 \pm 0.0013 \mathrm{~b}$ \\
P.popularis & $\mathrm{Control}$ & $41 \pm 3.13 \mathrm{~b}$ & $1,000 \pm 50.4 \mathrm{a}$ & $10.3 \pm 1.27 \mathrm{a}$ & $0.0354 \pm 0.0074 \mathrm{a}$ \\
& $\mathrm{NaCl}$ & $216 \pm 28.3 \mathrm{a}$ & $300 \pm 61.7 \mathrm{~b}$ & $0.7 \pm 0.23 \mathrm{~b}$ & $0.0073 \pm 0.0013 \mathrm{~b}$
\end{tabular}

Pn-PAR curves of mature leaves in upper shoot (leaf index number 6-8 from the shoot tip) were measured on day 13 at 8:30-10:00 a.m. over a range of PAR $\left(1,800 \rightarrow 20 \mu \mathrm{mol} \mathrm{m}^{-2} \mathrm{~s}^{-1}\right)$. Irradiance was controlled by a fan-cooled white Halogen light source, $T_{\text {air }}$ and $T_{\text {leaf }}$ was $29.6-41.3$ and $28.7-39.5^{\circ} \mathrm{C}$ during the observation period. Each value $( \pm \mathrm{SE})$ is the mean of three individual plants and values in the same column followed by different letters are significantly different $(P<0.05)$ between control and $\mathrm{NaCl}$ treatment

Table 2 Effects of $\mathrm{NaCl}$ on $\mathrm{CO}_{2}$ compensation point $(\mathrm{CCP}), \mathrm{CO}_{2}$ saturation point $(\mathrm{CSP}), \mathrm{CO}_{2}$ saturated $\mathrm{Pn}\left(\mathrm{CSP}{ }_{n}\right)$, and carboxylation efficiency (CE) in leaves of $P$. euphratica and $P$. popularis

\begin{tabular}{llclrr}
\hline Species & Treatments & CCP $\mu \mathrm{mol} \mathrm{mol}^{-1}$ & $\mathrm{CSP} \mu \mathrm{mol} \mathrm{mol}^{-1}$ & $\mathrm{CSPn}_{\mathrm{mmol} \mathrm{m}}^{-2} \mathrm{~s}^{-1}$ & $\mathrm{CE} \mathrm{mol} \mathrm{m}^{-2} \mathrm{~s}^{-1}$ \\
\hline P.euphratica & Control & $83 \pm 3.04 \mathrm{~b}$ & $703 \pm 62.36 \mathrm{a}$ & $9.5 \pm 1.32 \mathrm{a}$ & $0.0366 \pm 0.0049 \mathrm{a}$ \\
& $\mathrm{NaCl}$ & $109 \pm 4.15 \mathrm{a}$ & $467 \pm 42.36 \mathrm{~b}$ & $3.8 \pm 0.30 \mathrm{~b}$ & $0.0167 \pm 0.0062 \mathrm{~b}$ \\
P.popularis & Control & $89 \pm 8.36 \mathrm{~b}$ & $827 \pm 147.50 \mathrm{a}$ & $16.6 \pm 2.50 \mathrm{a}$ & $0.0452 \pm 0.0029 \mathrm{a}$ \\
& $\mathrm{NaCl}$ & $146 \pm 17.21 \mathrm{a}$ & $522 \pm 27.68 \mathrm{~b}$ & $4.2 \pm 0.81 \mathrm{~b}$ & $0.0226 \pm 0.0061 \mathrm{~b}$
\end{tabular}

$\mathrm{Pn}-\mathrm{Ci}$ curves of mature leaves in upper shoot (leaf index number 6-8 from the shoot tip) were measured on day 12 at 8:30-10:00 a.m. over a range of intercellular $\mathrm{CO}_{2}$ concentrations $(\mathrm{Ci})\left(0 \rightarrow 1,000 \mu \mathrm{mol} \mathrm{mol}^{-1}\right)$ controlled by a mini $\mathrm{CO}_{2}$ cartridge. PAR was $1,081-1,238 \mu \mathrm{mol}$ $\mathrm{m}^{-2} \mathrm{~s}^{-1}$ supplied by cool white fluorescent lamps supplemented with dysprosium lamps. $T_{\text {air }}$ and $T_{\text {leaf }}$ was $33.5-36.7$ and $33.0-37.1^{\circ} \mathrm{C}$ during the observation period. Each value $( \pm \mathrm{SE})$ is the mean of three individual plants and values in the same column followed by different letters are significantly different $(P<0.05)$ between control and $\mathrm{NaCl}$ treatment 
Table 3 Effects of $\mathrm{NaCl}$ on leaf chlorophyll $a$ fluorescence in P. euphratica and P. popularis

\begin{tabular}{|c|c|c|c|c|c|c|c|}
\hline \multirow[t]{2}{*}{ Days after treatment } & \multirow[t]{2}{*}{ Species } & \multirow[t]{2}{*}{ Treatments } & \multicolumn{5}{|c|}{ Chlorophyll a fluorescence parameters } \\
\hline & & & qP & $\mathrm{qN}$ & Fo & Fm & $\mathrm{Fv} / \mathrm{Fm}$ \\
\hline \multirow[t]{4}{*}{2} & P.euphratica & Control & $0.945 \pm 0.011 \mathrm{a}$ & $0.693 \pm 0.002 \mathrm{a}$ & $0.271 \pm 0.005 \mathrm{a}$ & $1.342 \pm 0.035 \mathrm{a}$ & $0.796 \pm 0.024 \mathrm{a}$ \\
\hline & & $\mathrm{NaCl}$ & $0.938 \pm 0.023 \mathrm{a}$ & $0.702 \pm 0.003 \mathrm{a}$ & $0.279 \pm 0.012 \mathrm{a}$ & $1.378 \pm 0.043 \mathrm{a}$ & $0.801 \pm 0.028 \mathrm{a}$ \\
\hline & P.popularis & Control & $0.992 \pm 0.007 \mathrm{a}$ & $0.846 \pm 0.006 \mathrm{a}$ & $0.369 \pm 0.034 \mathrm{a}$ & $2.050 \pm 0.014 \mathrm{a}$ & $0.818 \pm 0.021 \mathrm{a}$ \\
\hline & & $\mathrm{NaCl}$ & $0.994 \pm 0.004 \mathrm{a}$ & $0.792 \pm 0.002 \mathrm{a}$ & $0.371 \pm 0.010 \mathrm{a}$ & $2.055 \pm 0.062 \mathrm{a}$ & $0.820 \pm 0.042 \mathrm{a}$ \\
\hline \multirow[t]{4}{*}{12} & P.euphratica & Control & $0.819 \pm 0.014 \mathrm{a}$ & $0.831 \pm 0.022 \mathrm{a}$ & $0.240 \pm 0.026 \mathrm{a}$ & $1.258 \pm 0.051 \mathrm{a}$ & $0.811 \pm 0.027 \mathrm{a}$ \\
\hline & & $\mathrm{NaCl}$ & $0.792 \pm 0.024 \mathrm{a}$ & $0.852 \pm 0.001 \mathrm{a}$ & $0.264 \pm 0.032 \mathrm{a}$ & $1.525 \pm 0.067 \mathrm{a}$ & $0.825 \pm 0.026 \mathrm{a}$ \\
\hline & P.popularis & Control & $0.901 \pm 0.016 \mathrm{a}$ & $0.781 \pm 0.006 b$ & $0.334 \pm 0.008 b$ & $1.910 \pm 0.017 \mathrm{a}$ & $0.823 \pm 0.006 \mathrm{a}$ \\
\hline & & $\mathrm{NaCl}$ & $0.868 \pm 0.007 \mathrm{~b}$ & $0.918 \pm 0.001 \mathrm{a}$ & $0.377 \pm 0.036 \mathrm{a}$ & $1.643 \pm 0.032 b$ & $0.771 \pm 0.029 \mathrm{~b}$ \\
\hline
\end{tabular}

On day 2 and day 12, chlorophyll $a$ fluorescence was measured using the same leaf for gas exchange measurement (leaf index number 6-8 from the shoot tip) with a PAM-2100 Fluorometer (Heinz Walz GmbH, Germany) at 8:30-10:00 a.m. Half-hour dark-adapted leaves were used in this experiment and air temperature was $32.2-36.2^{\circ} \mathrm{C}$. The minimal fluorescence level (Fo) was determined by measuring modulated light $\left(<0.1 \mu \mathrm{mol} \mathrm{m} \mathrm{m}^{-2}\right)$ and the maximal fluorescence level (Fm) by a $0.8 \mathrm{~s}$ saturating pulse at $15,000 \mu \mathrm{mol} \mathrm{m}^{-2} \mathrm{~s}^{-1}$. Then the leaf was continuously illuminated with a white actinic light at a light intensity of $600 \mu \mathrm{mol} \mathrm{m}^{-2} \mathrm{~s}^{-1}$, the steady-state value of fluorescence (Fs) was reached within about 5-6 min and thereafter was recorded and a second saturating pulse at $15,000 \mu \mathrm{mol} \mathrm{m} \mathrm{m}^{-2} \mathrm{~s}^{-1}$ was imposed to determine the maximal fluorescence level in the light-adapted state $\left(\mathrm{Fm}^{\prime}\right)$. Based on the above mentioned measurements, following fluorescence parameters were calculated: (1) the maximal efficiency of PSII photochemistry in the dark-adapted state $(\mathrm{Fv} / \mathrm{Fm}),(2)$ the photochemical quenching coefficient $\mathrm{qP}=\left(\mathrm{Fm}^{\prime}-\mathrm{Fs}\right) /\left(\mathrm{Fm}^{\prime}-\mathrm{Fo}\right)$, and (3) nonphotochemical quenching coefficient $\mathrm{qN}=\left(\mathrm{Fm}-\mathrm{Fm}^{\prime}\right) /(\mathrm{Fm}-\mathrm{Fo})$. Each value $( \pm \mathrm{SE})$ is the mean of three plants and values in the same column followed by different letters are significantly different $(P<0.05)$ between control and $\mathrm{NaCl}$ treatment

the light-adapted state but markedly elevated coefficient of nonphotochemical quenching (qN) after 12 days of salt treatment, although they were not altered by the initial salinity (day 2) (Table 3). In contrast, there were no significant effects of salinity on chlorophyll $a$ fluorescence in P. euphratica during the period of salt stress (Table 3).

$\mathrm{Na}^{+}$and $\mathrm{Cl}^{-}$concentrations in the chloroplasts

$\mathrm{X}$-ray microanalysis showed that control $P$. euphratica plants had typically higher $\mathrm{Cl}^{-}$concentration $(58 \mathrm{mmol}$ $\mathrm{dm}^{-3}$ ) in the chloroplasts, as compared to control P. popularis plants $\left(32 \mathrm{mmol} \mathrm{dm}{ }^{-3}\right.$ ) (Fig. 2). Chloroplast $\mathrm{Na}^{+}$ was not detectable in control plants of both genotypes (Fig. 2). Significant accumulation of $\mathrm{Na}^{+}$in the chlorop-

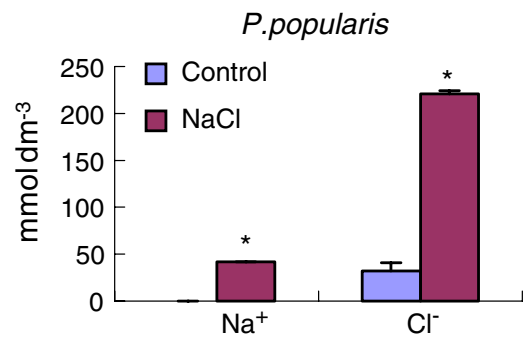

Fig. 2 Effects of $\mathrm{NaCl}$ on chloroplast $\mathrm{Na}^{+}$and $\mathrm{Cl}^{-}$concentration in $P$. euphratica and $P$. popularis leaves. Leaves in upper shoot (leaf index number 6-8 from shoot apex) were sampled on day 16. Leaf segments were vacuum freeze-dried, infiltrated in ether and polymerised with plastic. Samples were cut into $1 \mu \mathrm{m}$ thick sections for $\mathrm{X}$-ray microanalysis. Probe measurements were made on chloroplasts lasts was observed in the two poplars after 16 days of salinity, but $P$. popularis had 1.9 -fold higher $\mathrm{Na}^{+}$than $P$. euphratica (Fig. 2). Chloroplast $\mathrm{Cl}^{-}$in salinised P. popularis markedly increased to $221 \mathrm{mmol} \mathrm{dm}^{-3}$, which were 2.7 times of that in stressed P. euphratica plants (Fig. 2).

MDA content and membrane permeability

Compared with non-stressed plants, malondialdehyde (MDA) content and membrane permeability (MP) in $P$. popularis leaves remained unchanged in the first 12 days of salt stress, but increased by $120 \%$ (MDA) and 130\% (MP), respectively on day 16 (Fig. 3). In contrast, leaf MDA and MP in $P$. euphratica did not significantly increase during the period of salt stress (Fig. 3).

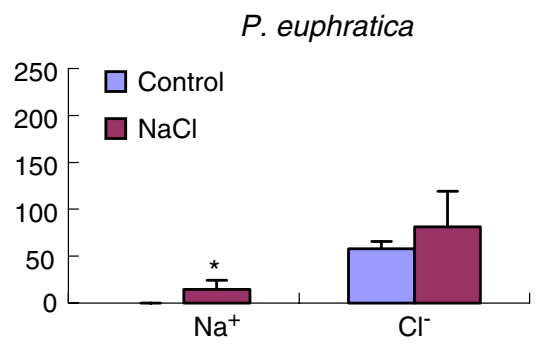

in spongy and palisade mesophyll cells and the magnification was at $\times 6350$. Ten to twenty measurements were taken from each leaf section. Each column is the mean of three plants and bars represent the standard error of the mean. Asterisk $\left(^{*}\right)$ means significant difference at $P<0.05$ 
Fig. 3 Effects of $\mathrm{NaCl}$ on MDA contents and membrane permeability (MP) (\%) in leaves of $P$. euphratica and $P$. popularis. Leaves in upper from shoot tip) were sampled in both genotypes. Each point is the mean of three plants and bars represent the standard error of the mean. Asterisk (*) at $P<0.05$ shoot (leaf index number 4-10 represents significant difference
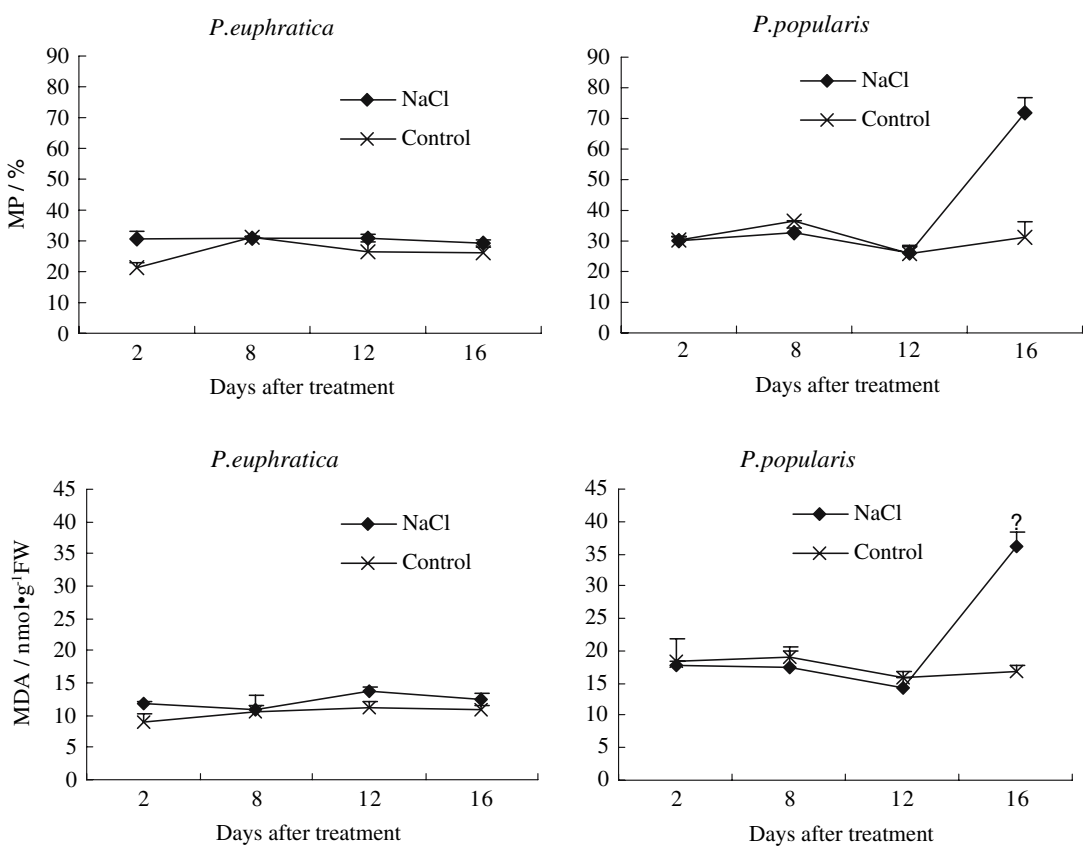

Isoenzyme patterns of SOD and POD under salinity

\section{SOD isoenzymes}

After gradient PAGE of crude leaf extracts, two SOD isoenzymes were detected in control plants of both genotypes although the pattern-with regard to migration and activities of isoenzymes was different (Fig. 4). KCN or $\mathrm{H}_{2} \mathrm{O}_{2}$ both inhibited activity of the two dominant SOD isoenzymes in both genotypes, indicating that these SOD isoenzymes were CuZn-SOD isoforms (Fig. 5). The activity of CuZn-SOD I and CuZn-SOD II in $P$. popularis was not detectable after 16 days of salt stress although they were not reduced on day 12 (Fig. 4). In comparison, there were no marked inhibitory effects of $\mathrm{NaCl}$ on the two SOD isoenzymes in $P$. euphratica during the period of observation (Fig. 4).

\section{POD isoenzymes}

Similarly, there were genotypic differences in the pattern of POD isoenzymes under control conditions although four distinct POD isoenzymes were observed in both genotypes (Fig. 4). Control P. popularis exhibited typically higher Pod 2 and Pod3 than control P. euphratica plants (Fig. 4). However, Pod 1 and Pod 2 were not detected in stressed $P$. popularis and the activity of $\operatorname{Pod} 3$ and $\operatorname{Pod} 4$ diminished with increasing the duration of salt stress (Fig. 4). In contrast, activities of POD isoforms in P. euphratica were remained almost unaltered during the period of salt treatment (Fig. 4).

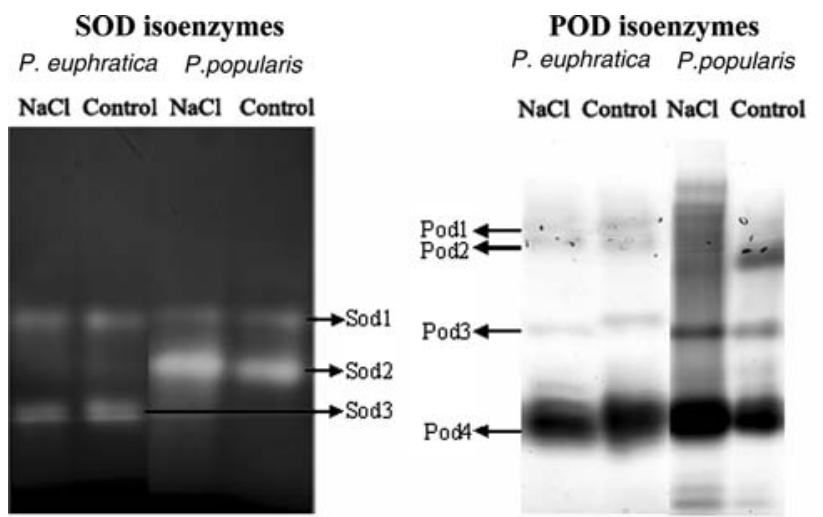

12 days after treatment
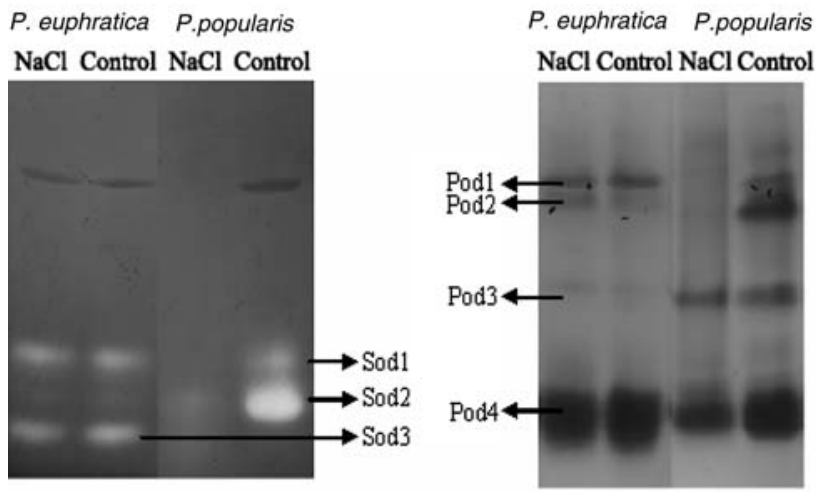

16 days after treatment

Fig. 4 Effects of $\mathrm{NaCl}$ on isoenzyme patterns of SOD and POD in leaves of $P$. euphratica and $P$. popularis. Leaves in upper shoot (leaf index number 4-10 from shoot apex) were sampled in both genotypes. In each track $30 \mu \mathrm{g}$ of soluble protein were applied to native polyacrylamide gel electrophoresis at $4^{\circ} \mathrm{C}$ using a stacking gel $(4 \% \mathrm{w} / \mathrm{v})$ and a separating gel $(10 \% \mathrm{w} / \mathrm{v})$ 


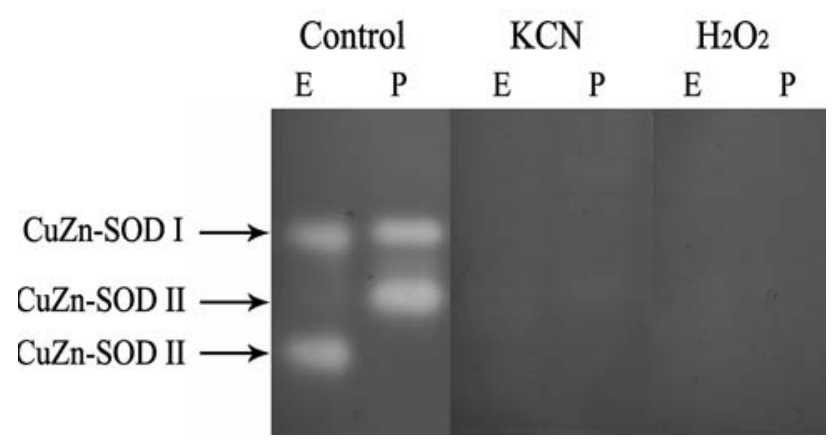

Fig. 5 Densitometric analysis of non-denaturing activities gels of SOD isoforms from $P$. euphratica $(E)$ and $P$. popularis $(P)$ leaves. Leaves in upper shoot (leaf index number 4-10 from shoot apex) were sampled in both genotypes. In each track $30 \mu \mathrm{g}$ of soluble protein were applied to native polyacrylamide gel electrophoresis at $4^{\circ} \mathrm{C}$ using a stacking gel $(4 \% \mathrm{w} / \mathrm{v})$ and a separating gel $(10 \% \mathrm{w} / \mathrm{v})$. Identification of SOD isoforms was performed by pre-incubation of gels with inhibitors $\left(5 \mathrm{mmol} / \mathrm{L} \mathrm{KCN}\right.$ and $10 \mathrm{mmol} / \mathrm{L} \mathrm{H}_{2} \mathrm{O}_{2}$ )

\section{Discussion}

Photosynthetic response to salinity

Unlike $P$. popularis, $P$. euphratica plants exhibited a rapid decline of gas exchange in response to the initiation of salt stress (Fig. 1). The decline of Pn and TRN was mainly resulted from the stomatal closure (Fig. 1). It can be inferred that salt-induced inhibition of photosynthesis was not due to ion toxicity caused by a lower soil salt; rather it presumably was a function of signal from the roots. Chen and colleagues reported that xylem abscisic acid (ABA) concentration increased more rapidly in $P$. euphratica than other salt-sensitive poplar genotypes, e.g. a hybrid of $P$. euphratica, $P$. talassica $\operatorname{Kom} \times(P$. euphratica + Salix alba L.) and $P$. popularis (Chen et al. 2001, 2002a). Recently, we found that the stomatal closure in $P$. euphratica was associated with a rapid increase of endogenous ABA and calmodulin (CaM) (Chang et al. 2006). Therefore, the salt-induced elevation of stress signals, e.g. $\mathrm{ABA}, \mathrm{Ca}^{2+} /$ $\mathrm{CAM}$, caused the stomatal closure and reduced the gas exchange. The reduced water flow would limit the amount of root-to-shoot salt transport (Chen et al. 2002a). The insensitivity of $P$. popularis to salt stress implies that this genotype was not able to trigger the initial adjustments that conferring salt tolerance after the onset of salt stress (Chen et al. 2001, 2002a).

In a longer-term of salinity, $P$. popularis plants exhibited a great reduction of photosynthesis, whereas stressed $P$. euphratica retained a relatively higher capacity for $\mathrm{CO}_{2}$ assimilation (Fig. 1). Drastic decline of Gs in salt-stressed $P$. popularis indicated that the reduced Pn was mainly the limited diffusion of $\mathrm{CO}_{2}$ in the leaves through a decrease of stomatal and mesophyll conductances (Flexas et al. 2004;
Grassi and Magnani 2005). Pn-Ci curves exhibited lower values of $\mathrm{CO}_{2}$ saturation point (CSP), $\mathrm{CO}_{2}$ saturated $\mathrm{Pn}$ $\left(\mathrm{CSP}_{n}\right)$ and carboxylation efficiency (CE) in control plants of both genotypes as compared to what is usual in poplars (Table 2), mainly resulting from the higher air temperature $\left(33.5-36.7^{\circ} \mathrm{C}\right)$ and leaf temperature $\left(33.0-37.1^{\circ} \mathrm{C}\right)$ during the observation period. Salt stress reduced the carboxylation efficiency by a similar magnitude $(50-54 \%)$ in $P$. popularis and $P$. euphratica (Table 2), however, the inhibitory effect of $\mathrm{NaCl}$ on light reaction was significantly different in the two tested genotypes (Table 1). $\mathrm{NaCl}$ caused a higher restriction on apparent quantum yield (AQY), light saturation point (LSP), and light saturated Pn $\left(\mathrm{LSP}_{n}\right)$ in $P$. popularis, as compared to $P$. euphratica (Table 1). Chlorophyll $a$ fluorescence data indicated that a longer-term of salt stress (12 days) decreased the maximal efficiency of PSII photochemistry $(\mathrm{Fv} / \mathrm{Fm})$ in the darkadapted state and photochemical quenching (qP) in the light-adapted state (Table 3). The salt-induced increase of Fo and the marked decline of Fm in P. popularis imply the inhibitory effects of chloroplast salt ions on PSII reaction centre although the elevated coefficient of nonphotochemical quenching (qN) may serve to dissipate excess excitation energy (Table 3).

Salt accumulation in chloroplasts, SOD and POD isoenzymes and lipid peroxidation under salt stress

The restriction of Pn in $P$. popularis appears to be a consequence (at least in part) of salt entry into the chloroplasts. Salt ions transport from root to shoot via transpiration stream and accumulate in leaf apoplast after water evaporates from leaf. High $\mathrm{Na}^{+}$and $\mathrm{Cl}^{-}$in the mesophyll cell walls of $P$. popularis (data not shown) brought about an osmotic shock (Oertli 1968; Greenway and Munns 1980; Flowers and Yeo 1986). Moreover, salinity markedly increased chloroplast $\mathrm{Na}^{+}$and $\mathrm{Cl}^{-}$in $P$. popularis, especially $\mathrm{Cl}^{-}$(Fig. 2). Great buildup of $\mathrm{Na}^{+}$and $\mathrm{Cl}^{-}$in chloroplasts may directly cause ion toxicity and induce the subsequent oxidative stress (Hernández et al. 1993, 1995, 1999; Gosset et al. 1996; Gómez et al. 1999; Savouré et al. 1999). The activity of $\mathrm{CuZn-SOD}$ isoenzymes in $P$. popularis was not detectable at the end of experiment and the reduction of POD isoenzymes increased with increasing exposure period (Fig. 4). Salt-induced decline of SOD and POD isoenzymes suggests the reduced ability in reactive oxygen species (ROS) elimination. ROS may initiate membrane lipid peroxidation, leading to reduced membrane lipid unsaturation and membrane protein polymerization, thus, results in an increase of membrane permeability (Chen 1991). In this study, the membrane permeability in $P$. popularis increased with MDA under salt stress (Fig. 3). We conclude the decline of SOD and POD isoenzymes accelerated lipid 
peroxidation and membrane permeability, which in turns resulted in more salt entry into the cytoplasm and chloroplast. The buildup of salt ions in chloroplasts may exhibit negative effects on light and dark reactions, resulting in a photosynthesis drop in P. popularis (Fig. 1).

In contrast to $P$. popularis, $P$. euphratica maintained activity of SOD and POD isoenzymes during the period of salt stress (Fig. 4), correspondingly, there was no significant increase of MDA and membrane permeability in stressed plants (Fig. 3). Compared with control plants, chloroplast $\mathrm{Na}^{+}$increased to $15 \mathrm{mmol} \mathrm{dm}{ }^{-3}$ and $\mathrm{Cl}^{-}$increased by $41 \%$ in $\mathrm{NaCl}$-stressed plants, which were much lower than salinised $P$. popularis (Fig. 2). The lower salt buildup in chloroplasts may partly result from the effective $\mathrm{Na}^{+} / \mathrm{H}^{+}$antiporters in $P$. euphratica, PeNhaD1. Under saline conditions, the transcript levels of PeNhaDl were maintained in $P$. euphratica but collapsed in a salt-sensitive genotype, $P$. canescens (Ottow et al. 2005b). Moreover, salinity increased the activity of plasma membrane $\mathrm{H}^{+}$-ATPase- $\mathrm{H}^{+}$pumps in $P$. euphratica cells (our unpublished data). Accordingly, P. euphratica was able to drive toxic $\mathrm{Na}^{+}$ions out of the cytoplasm via $\mathrm{Na}^{+} / \mathrm{H}^{+}$antiporter systems. Therefore, less salt ions accumulated in the chloroplasts of mesophyll cells, the photosynthesis of $P$. euphratica was less restricted.

In conclusion, salinity restricted $\mathrm{CO}_{2}$ assimilation in the two genotypes, but a more pronounced inhibitory effects was observed in the salt-sensitive genotype, $P$. popularis as compared to the salt-tolerant genotype, $P$. euphratica. The reduced Pn in both poplars was mainly the result of decreased stomatal and mesophyll conductances, which causing a lower $\mathrm{CO}_{2}$ concentration in chloroplasts of stressed leaves. Furthermore, great buildup of $\mathrm{Na}^{+}$and $\mathrm{Cl}^{-}$in chloroplasts of $P$. popularis may exhibit direct and indirect restrictions on dark and light reactions. Salt-induced decline of SOD and POD isoenzymes in P. popularis would reduce the free radical scavenging ability of the cell, leading to a variety of toxic responses to uncontrolled oxidation, thus resulted in lipid peroxidation and ion entry into the cytoplasm. In comparison, stressed $P$. euphratica plants restricted the salt influx into the chloroplasts and maintained activity of SOD and POD isoenzymes, the photosynthetic capacity of $P$. euphratica was consequently less restricted.

Acknowledgments The research was supported jointly by Alexander von Humboldt-Stiftung/Foundation (Germany), German Science Foundation through Poplar Research Group Germany (PRG), the key project of National Natural Science Foundation of China (30430430), National Program for High Technology Research and Development (863) of China (No.2006AA10Z131), a Foundation for the Author of National Excellent Doctoral Dissertation of PR China (200152), and the Teaching and Research Award Program for Outstanding Young Teachers in Higher Education Institution of MOE, PRC (2002-323). We thank Dr. Andrea Olbrich for valuable help with operating the microscope, Haiyuan Ma, Liyuan Liu, He Li, Haijiao Weng, Zhiyong
Hao, Shuang Yang, Shan Duan and Jie Jiang for assistance in greenhouse and laboratory.

\section{References}

Almansa MS, del Río LA, Alcaraz C, Sevilla F (1989) Isoenzyme pattern of superoxide dismutase in different varieties of Citrus plants. Physiol Plant 76:563-568

Alscher RG, Erturk N, Heath LS (2002) Role of superoxide dismutases in controlling oxidative stress in plants. J Exp Bot 53(372):1331-1341

Asada K (1994) Production and action of active oxygen in photosynthetic tissues. In: Foyer $\mathrm{CH}$, Mullineaux PM (eds) Causes of photooxidative stress and amelioration of defense system in plants. CRC, Boca Raton pp 77-104

Asada K, Takahashi M (1987) Production and scavenging of active oxygen in photosynthesis. In: Kyle DJ, Osmond CB, Arntzen CJ (eds) Photoinhibition. Elsevier, Amsterdam, pp 227-287

Badawi GH, Yamauchi Y, Shimada E, Sasaki R, Kawano N, Tanaka K (2004) Enhanced tolerance to salt stress and water deficit by overexpressing superoxide dismutase in tobacco (Nicotiana tabacum) chloroplasts. Plant Sci 166:919-928

Beauchamp C, Fridovich I (1971) Superoxide dismutase: improved assays and an assay applicable to acrylamide gels. Anal Biochem 44:276-287

Bowler C, Van Montagu M, Inze D (1992) Superoxide dismutase and stress tolerance. Ann Rev Plant Physiol Plant Mol Biol 43:83116

Bradford MM (1976) A rapid and sensitive method for the quantification of microgram quantities of protein utilizing the principle of protein-dye binding. Anal Biochem 72:248-254

Bridges SM, Salin ML (1981) Distribution of iron-containing superoxide dismutase in vascular plants. Plant Physiol 68:275278

Chang Y, Chen S, Yin W, Wang R, Liu Y, Shi Y, Shen Y, Li Y, Jiang J, Liu Y (2006) Growth, gas exchange, ABA and CaM response to salt stress in three poplars. J Integr Plant Biol 48:286-293

Chen S (1991) Injury of membrane lipid peroxidation to plant cell. Plant Physiol Commun 27(2):84-90 (in Chinese)

Chen S, Li J, Wang S, Hüttermann A, Altman A (2001) Salt, nutrient uptake and transport, and ABA of Populus euphratica; a hybrid in response to increasing soil $\mathrm{NaCl}$. Trees 15:186-194

Chen S, Li J, Wang T, Wang S, Polle A, Hüttermann A (2002a) Osmotic stress and ion-specific effects on xylem abscisic acid and the relevance to salinity tolerance in poplar. J Plant Growth Regul 21:224-233

Chen S, Li J, Fritz E, Wang S, Hüttermann A (2002b) Sodium and chloride distribution in roots and transport in three poplar genotypes under increasing $\mathrm{NaCl}$ stress. For Ecol Manage 168:217-230

Chen S, Li J, Wang S, Fritz E, Hüttermann A, Altman A (2003) Effects of $\mathrm{NaCl}$ on shoot growth, transpiration, ion compartmentation and transport in regenerated plants of Populus euphratica and Populus tomentosa. Can J For Res 33:967-975

Dhindsa RS, Plumb-Dhindsa P, Thorpe TA (1981) Leaf senescence: correlated with increased levels of membrane permeability and lipid peroxidation, and decreased levels of superoxide dismutase and catalse. J Exp Bot 32:93-101

Elstner EF (1987) Metabolism of activated oxygen species. In: Davies DD (ed) The biochemistry of plants. Biochemistry of metabolism, vol 11. Academic, San Diego, pp 253-315

Flexas J, Bota1 J, Loreto F, Cornic G, Sharkey TD (2004) Diffusive and metabolic limitations to photosynthesis under drought and salinity in C3 plants. Plant Biol 6:269-279 
Flowers TJ, Yeo AR (1986) Ion relations of plants under drought and salinity. Aust J Plant Physiol 13:75-91

Fridovich I (1986) Superoxide dismutase. Adv Enzymol Relat Areas Mol Biol 58:61-97

Fritz E (1989) X-ray microanalysis of diffusible elements in plant cells after freeze-drying, pressure-infiltration with ether and embedding in plastic. Scan Microsc 3(2):517-526

Fritz E, Jentschke G (1994) Agar standard for quantitative X-ray microanalysis of resin-embedded plant tissues. J Microsc 174:47-50

Fung L, Wang S, Altman A, Hüttermann A (1998) Effect of $\mathrm{NaCl}$ on growth, photosynthesis, ion and water relations of four poplar genotypes. For Ecol Manage 107:135-146

Gómez JM, Hernández JA, Jiménez A, del Río LA, Sevilla F (1999) Differential response of antioxidative enzymes of chloroplasts and mitochondria to long-term $\mathrm{NaCl}$ stress of pea plants. Free Rad Res 31:S11-S18

Gosset DR, Banks SW, Millhollon EP, Lucas MC (1996) Antioxidant response to $\mathrm{NaCl}$ stress in a control and a $\mathrm{NaCl}$-tolerant cotton cell line grown in the presence of paraquat, buthionine sulfoximine, and exogenous glutathione. Plant Physiol 112:803-809

Grassi G, Magnani F (2005) Stomatal, mesophyll conductance and biochemical limitations to photosynthesis as affected by drought and leaf ontogeny in ash and oak trees. Plant Cell Environ 28:834-849

Greenway H, Munns R (1980) Mechanisms of salt tolerance in nonhalophytes. Ann Rev Plant Physiol 31:149-190

Hassan HM, Scandalios JM (1990) Superoxide dismutases in aerobic organisms. In: Alscher RG, Cumming JR (eds) Stress responses in plants: adaptation and acclimatation mechanisms. Wiley-Liss, New York, pp 175-199

Heath RL, Packer L (1968) Photoperoxidation in isolated chloroplasts. I. Kinetigs and stoichiometry of fatty acid peroxidation. Arch Biochem Biophys 125:189-198

Hernández JA, Corpas FJ, Gómez M, del Río LA, Sevilla F (1993) Salt-induced oxidative stress mediated by activated oxygen species in pea leaf mitochondria. Physiol Plant 89:103-110

Hernández JA, Olmos E, Corpas FJ, Sevilla F, del Río LA (1995) Salt-induced oxidative stress in chloroplast of pea plants. Plant Sci 105:151-167

Hernández JA, Campillo A, Jiménez A, Alarcón JJ, Sevilla F (1999) Response of antioxidant systems and leaf water relations to $\mathrm{NaCl}$ stress in pea plants. New Phytol 141:241-251
Hernández JA, Jiménez A, Mullineaux P, Sevilla F (2000) Tolerance of pea (Pisum sativum L.) to long-term salt stress is associated with induction of antioxidant defenses. Plant Cell Environ 23:853-862

Ma H, Fung L, Wang S, Altman A, Hüttermann A (1997) Photosynthesis response of Populus euphratica to salt stress. For Ecol Manage 93:55-61

Oertli JJ (1968) Extracellular salt accumulation, a possible mechanism of salt injury in plants. Agrochim 12:461-469

Ottow EA, Brinker M, Teichmann T, Fritz E, Kaiser W, Brosché M, Kangasjärvi J, Jiang X, Polle A (2005a) Populus euphratica displays apoplastic sodium accumulation, osmotic adjustment by decreases in calcium and soluble carbohydrates, and develops leaf succulence under salt stress. Plant Physiol 139:1762-1772

Ottow EA, Polle A, Brosché M, Kangasjärvi J, Dibrov P, Zörb C, Teichmann T (2005b) Molecular characterization of PeNhaD1: the first member of the $\mathrm{NhaD} \mathrm{Na} / \mathrm{H}^{+}$antiporter family of plant origin. Plant Mol Biol 58:73-86

Ros Barceló A, Muñoz R, Sabater F (1987) Lupin peroxidases I. Isolation and characterization of cell wall-bound isoperoxidase activity. Physiol Plant 71:448-454

Savouré A, Thorin D, Davey M, Hua XJ, Mauro S, Van Montagu M, Inzé $\mathrm{D}$, Verbruggen $\mathrm{N}$ (1999) $\mathrm{NaCl}$ and $\mathrm{CuSO}_{4}$ treatments trigger distinct oxidative defense mechanism in Nicotiana plumbaginifolia L. Plant Cell Environ 22:387-396

Shigeoka S, Ishikawa T, Tamoi M, Miyagawa Y, Takeda T, Yabuta Y, Yoshimura K (2002) Regulation and function of ascorbate peroxidase isoenzymes. J Exp Bot 53:1305-1319

Takahashi MA, Asada K (1983) Superoxide anion permeability of phospholipid membrane and chloroplast thylakoids. Arch Biochem Biophys 226:558-566

Tsugane K, Koboyashi K, Niwa Y, Ohba Y, Wada K, Kobayashi H (1999) A recessive Arabidopsis mutant that grows photoautotrophically under salt stress shows enhanced active oxygen detoxification. Plant Cell 11:1195-1206

Wang Y, Ying Y, Chen J, Wang X (2004) Transgenic Arabidopsis overexpressing Mn-SOD enhanced salt-tolerance. Plant Sci 167:671-677

Wang R, Chen S, Ma H, Liu L, Li H, Weng H, Hao Z, Yang S (2006) Genotypic differences in antioxidative stress and salt tolerance of three poplars under salt stress. Front For Chin 1:82-88 